Research Article

\title{
The Relationship between Academic Procrastination and Academic Performance of Freshmen Students from a Teacher Education Institution
}

\author{
John Mark R. Asio ${ }^{1}$ \\ ${ }^{1}$ Research Development and Community Extension Services, Gordon College, \\ Olongapo City, Philippines.
}

\section{Article History \\ Received: \\ 02.10 .2020}

Revised:

24.11.2020

Accepted:

17.12.2020

*Corresponding Author:

John Mark R. Asio

Email:

asio.johnmark@gmail.com

This is an open access article, licensed under: $\mathrm{CC}-\mathrm{BY}-\mathrm{SA}$

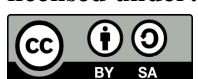

Abstract: The academic environment is full of challenges and obstacles. With this idea, students promote some unconventional practices in studying. One of which is academic procrastination. This study analyzed the relationship between academic procrastination and academic performance of freshmen students from a teacher education institution. The researcher used a descriptive-correlational research design for this study. Ninety (90) freshmen students took part in the survey using a convenience sampling technique in the academic year of 2018-2019. This study used an adapted instrument for data gathering through a survey. The study also utilized SPSS 20 to analyze the data. Results showed that the respondents procrastinate in their academic activities. In terms of academic performance, professional education subjects got the lowest rating score and the major subjects got the highest. In addition, the program, scholarship status, and religion of the respondents got significant statistical differences. Furthermore, the study also obtained a low indirect relationship between academic procrastination, general education subjects, and professional education subjects. From the findings of the study, the researcher provided pertinent recommendations for parents, students, instructors and the institution.

Keywords: Academic Performance, Academic Procrastination, Freshmen Students, Teacher Education Institution. 


\section{Introduction}

The $21^{\text {st }}$-century offers a variety of changes in the behaviors and attitudes of students. But there is one idea that has been proliferating through the years, it is about procrastination. A student-adviser provided a simple definition of procrastination [1]. With the different gadgets and equipment that thrive along the way, it will affect learning and studying to some extent. However, other factors play along with the ever-growing strain of the academic perseverance of students.

Procrastination can affect all forms of academic misconduct [2], factors influencing the learning process [3], and demographic characteristics [4]. However, a study, posited that time perspective has an indirect effect on procrastination [5], and at the same time another research paper also showed that active procrastination is related to creative self-efficacy [6]. On a different study, suggested interventions to help students overcome their procrastinating tendencies [7]. Also, another researcher provided insights regarding procrastination and its effect on students' earning process [8].

The main aim of this study is to analyze the demographic profiles, level of academic procrastination, and academic performance of the freshmen students in a teacher education institution. At the same time determine if there is a relationship between their academic procrastination and their academic performance based on the results of their GPAs in 3 different areas namely, major subject(s), general education subjects, and their professional education subjects. From the findings of the study, the researchers will formulate an intervention program that will help students in their academic performances.

The study also intends to create harmony in the academic performances of the student by giving the faculty or instructors the idea which subjects do they have difficulty in dealing with most of the time. This result of the study can also benefit students and parents by providing them an idea of how to cope up with the stress of accomplishing and complying with the requirements of each subject area.

\section{Literature Review}

In terms of relationship, procrastination is associated with coping [9], negatively related to academic performance $[4,10]$, and course achievement [11]. But procrastination can also be associated with other factors such as self-esteem, depression, and loneliness [12], and socially prescribed perfectionism and self-oriented perfectionism [13]. Another study showed the relationship between procrastination and anxiety at the same time low levels of self-efficacy for a regulation [14]. On the other hand, a study also found out that extraversion and neuroticism relate to active procrastination [5].

Gender plays a role between academic procrastination and academic performance [10]. Additionally, A group of researchers endorsed that self-regulation predicts procrastination positively and negatively [16]. Another study also predicted academic procrastination regarding course achievement, and predictability is increased as time passed [11]. Furthermore, perfectionism predicted academic engagement and procrastination [13]. Another study extrapolated that active procrastination predicts GPA [14]. However, the trajectories of procrastination and anxiety were not predicted [15]. To add, collective coping style, avoidant coping style, academic self-efficacy, and English language proficiency predicted academic procrastination in non-Indian Asian international students [17].

Other relative findings include the tendency of procrastination in terms of year level [18], motivating students to persist academic procrastination [19], problematic smartphone use predicted academic procrastination [20], and college students with psychosocial problems are more vulnerable to procrastination [12]. However, a study showed that online SMART-type goal clarification can lead to positive changes in academic procrastination of college students [21]. Also, another study showed that committed action is moderately related to procrastination [22]. Another paper also stated that procrastination associates with insomnia symptoms [23].

Based on the different perspectives of different authors and studies, we observe varying results and issues. And due to this, the author intended to investigate a new in line with the gaps observed in the literature reviews and the context that this study aimed for.

\section{Methodology}

\subsection{Research Design}

This study made use of a descriptive-correlation design using a survey questionnaire as its main instrument in obtaining pertinent information related to the main objectives of the research. Since the study intends to assess the effects of procrastination on the academic achievements of freshmen 
students, the descriptive design is anticipated for it tries to analyze or describe a definite characteristic or trait of a certain population or group.

\subsection{Respondents}

A total of 90 freshmen students participated in this study using a purposive sampling technique (see Table 1). The respondents were all students of the teacher education institution, regardless of whatever course they are currently enrolled in the current semester of the Academic Year 2018-2019.

Table 1. Demographic Profile of the Respondents

Frequency

Program

BSED-Science

BSED-Mathematics

BSED-English

BCAEd

BPEd

Age

15-20 years old

21-25 years old

26-30 years old

Sex

Male

Female

Religion

Roman Catholic

Iglesia ni Cristo

Born Again Christian

Others

Scholar Status

Student-Scholar

Non-Student-Scholar

Total
80

12

6

39

10

23

7

3

38

52

53

11

14

10

49

45

90
Percentage

26

89

8

3

42

58

61

12

16

11

52

48

100

\subsection{Research Instrument}

The researcher adopted and modified an instrument from McCloskey \& Scielzo's Academic Procrastination Scale (APS) to gauge the prevalence of procrastination of the respondents. Before the administration of the survey, the instrument was first pre-tested to other college students who are not part of the study for any ambiguous or misunderstood terms or words. 


\subsection{Statistical Analysis}

This study used frequency count and percentage for the demographic profile of the respondents. The researcher also used mean and standard deviation for the academic procrastination responses and the academic achievement of the respondents. For statistical inferences, the researcher used t-test, ANOVA, and Pearson-r to analyze and interpret the gathered and tabulated data with the help of Microsoft Excel and SPSS version 20. This study also used a four (4) point Likert Scale for the answer of the respondents.

Table 2. Academic Procrastination Scale Result

\begin{tabular}{|c|c|c|}
\hline Statement & Mean & Interpretation \\
\hline I usually allocate time to review and proofread my work.* & 3.10 & Agree \\
\hline I put off projects until the last minute. & 2.60 & Agree \\
\hline $\begin{array}{l}\text { I have found myself waiting until the day before to start a big } \\
\text { project. }\end{array}$ & 2.51 & Agree \\
\hline I know I should work on schoolwork, but I just don't do it. & 2.27 & Disagree \\
\hline $\begin{array}{l}\text { When working on schoolwork, I usually get distracted by other } \\
\text { things. }\end{array}$ & 2.77 & Agree \\
\hline I waste a lot of time on unimportant things. & 2.48 & Disagree \\
\hline $\begin{array}{l}\text { I get distracted by other, more fun, things when I am supposed to } \\
\text { work on schoolwork. }\end{array}$ & 2.72 & Agree \\
\hline I concentrate on schoolwork instead of other distractions. * & 2.79 & Agree \\
\hline $\begin{array}{l}\text { I can't focus on schoolwork or projects for more than an hour until } \\
\text { I get distracted. }\end{array}$ & 2.38 & Disagree \\
\hline My attention span for schoolwork is very short. & 2.27 & Disagree \\
\hline Tests are meant to be studied for just the night before. & 2.66 & Agree \\
\hline I feel prepared well in advance for most tests. * & 2.62 & Agree \\
\hline $\begin{array}{l}\text { "Cramming" and last-minute studying is the best way that I study } \\
\text { for a big test. }\end{array}$ & 2.52 & Agree \\
\hline $\begin{array}{l}\text { I allocate time so I don't have to "cram" at the end of the } \\
\text { semester.* }\end{array}$ & 2.63 & Agree \\
\hline I only study the night before exams. & 2.61 & Agree \\
\hline If an assignment is due at midnight, I will work on it until 11:59. & 2.48 & Disagree \\
\hline $\begin{array}{l}\text { When given an assignment, I usually put it away and forget about } \\
\text { it until it is almost due. }\end{array}$ & 2.24 & Disagree \\
\hline Friends usually distract me from schoolwork. & 2.32 & Disagree \\
\hline $\begin{array}{l}\text { I find myself talking to friends or family instead of working on } \\
\text { school work. }\end{array}$ & 2.51 & Agree \\
\hline $\begin{array}{l}\text { On the weekends, I make plans to do homework and projects, but } \\
\text { I get distracted and hang out with friends. }\end{array}$ & 2.53 & Agree \\
\hline
\end{tabular}


I tend to put off things for the next day.

I don't spend much time studying school material until the end of the semester.

I frequently find myself putting important deadlines off.

If I don't understand something, I'll usually wait until the night before a test to figure it out.

I read the textbook and look over notes before coming to class and listening to a lecture or teacher. *
2.57

2.27

2.36

2.63
Agree

Disagree

Disagree

Disagree

Agree

\begin{tabular}{lll}
\hline Overall Mean & $\mathbf{2 . 5 3}$ & Agree \\
\hline$*$ Likert Scale: $1.00-1.49-$ Strongly Disagree;
\end{tabular}

1.50-2.49 - Disagree; 2.50-3.49 - Agree;

3.50-4.00 - Strongly Agree

\section{Results}

The study aimed to analyze the relationship between the academic procrastination and academic performance of freshmen students from a teacher education institution. The researchers gathered data, tabulated, and subjected it to statistical treatment for analysis. The following Tables represent the results of the data from the respondents.

Table 2 represents the result of the Academic Procrastination survey. As seen from the table, 15 out of the 25 items of the survey garnered a response of "agree". The remaining 10 items gathered a response of "disagree". The highest mean score belonged to item 1 with 3.10, which has a Likert scale interpretation of "agree". But the lowest mean score went to item 17 with 2.24, which corresponds to "disagree" on the Likert scale. The overall mean is 2.53 which falls under the Likert scale interpretation of "agree". This only means that the respondents admit the fact that they do exercise the concept of academic procrastination from time to time.

Table 3. Average Marks per Subject Areas of the Respondents

\begin{tabular}{lllc}
\hline & Mean & SD & Verbal Interpretation \\
\hline General Education Subjects & 89.34 & 4.34 & Very Good \\
Major Subjects & 89.76 & 3.23 & Very Good \\
Professional Education Subjects & 86.10 & 4.05 & Good \\
Grade Point Average (GPA) & 88.58 & 3.01 & Very Good \\
\hline Legend: $\quad$ 97-100= Excellent; 93-96= Superior; & & \\
$\quad$ 89-92= Very Good; 85-88= Good; & & \\
$\quad$ 80-84= Satisfactory; 75-79=Fair; & & & \\
$\quad$ 74 below = Needs Improvement & & &
\end{tabular}

Table 3 shows the average marks of the respondents per subject area in their course. We observed that the average rating for the general education subjects is $89.34(\mathrm{SD}=4.34)$ which has a corresponding verbal interpretation of "very good". While the major subjects got an average rating of $89.76(\mathrm{SD}=3.23)$ also with a verbal interpretation of "very good". However, professional education subjects got an average rating of $86.10(\mathrm{SD}=4.05)$ which has an equivalent verbal interpretation of "good". To cap it all up, the grade point average (GPA) got an average rating of $88.58(\mathrm{SD}=3.01)$ which corresponds to "very good". This result only shows that the respondents have a harder time studying in professional education subjects since they got a lower average score in this area. On the 
other hand, general education subjects and major subjects got better scores since students tend to concentrate in these areas more than the professional education subjects.

Table 4. Differences in Response in terms of Sex and Scholarship Status

\begin{tabular}{lcccc}
\hline Demographic Profiles & \multicolumn{4}{c}{ Academic Procrastination } \\
\cline { 2 - 5 } & M & SD & $t$-value & $p$-value \\
\hline Male $(n=38)$ & 2.59 & 0.33 & 1.74 & .086 \\
Female $(n=52)$ & 2.48 & 0.28 & & \\
\hline Scholar $(n=49)$ & 2.60 & 0.31 & $2.33^{*}$ & .022 \\
Non-scholar $(n=41)$ & 2.45 & 0.28 & & \\
\hline
\end{tabular}

$d f=88 ;{ }^{*} p<0.05$

Table 4 represents the $t$-test to compare the scores of academic procrastinations and the profile variables of the respondents. There was no significant difference in the scores of males $(M=2.59, S D$ $=0.33)$ with that of the females $(M=2.48, S D=0.28) ; t(88)=1.74, p=.086$. This means that regardless of sex, procrastination is prevalent. However, there is a significant difference in the scores between a student scholar $(M=2.60, S D=0.31)$ and non-student scholar $(M=2.45, S D=0.28) ; t(88)$ $=2.33, p=0.022$. This means that student scholars tend to procrastinate more often than the nonstudent scholars.

Table 5. Differences in Respondents' Academic Procrastination Grouped According to Demographic Profile

\begin{tabular}{lllllll}
\hline & & $\mathrm{SS}$ & $\mathrm{dF}$ & $\mathrm{MS}$ & $F$ value & $p$-value \\
\hline Program & Between Groups & 1.334 & 4 & .333 & $4.184^{*}$ & .004 \\
& Within & 6.773 & 85 & .080 & & \\
Age & Total & 8.107 & 89 & & & \\
& Between Groups & .400 & 2 & .200 & 2.259 & .111 \\
Religion & Within & 7.706 & 87 & .089 & & \\
& Total & 8.107 & 89 & & & \\
& Between Groups & .890 & 3 & .297 & $3.534^{*}$ & .018 \\
& Within & 7.217 & 86 & .084 & & \\
\hline
\end{tabular}

$* p<.05$

Table 5 shows the Analysis of Variance (ANOVA) to compare the academic procrastination of the respondents. The result of the ANOVA indicated that there is a significant difference observed in terms of the program, $F(4,85)=4.184, p=.004$, and religion $F(3,86)=3.534, p=.018$. This is because their $p$ values are higher than the Alpha significance level of .05. This means that since the respondents belong to different programs and religious affiliations, both variables can affect the respondent's responses to academic procrastination. 
However, there are no significant differences found in age, $F(2,87)=2.259, p=0.111$. This is because the $p$ values are higher than the Alpha level of significance of .05. This means that regardless of age and average monthly family income, these variables do not affect their academic procrastination concept.

Table 6. Differences in Responses in terms of Subject Areas

\begin{tabular}{lllllll}
\hline & & SS & dF & MS & $\begin{array}{c}F \\
\text { value }\end{array}$ & $p$-value \\
\hline Major Subjects & Between Groups & 3.814 & 31 & 0.123 & $1.663^{*}$ & .047 \\
& Within & 4.292 & 58 & 0.074 & & \\
& Total & 8.107 & 89 & & & \\
General Education & Between Groups & 7.440 & 80 & 0.093 & 1.257 & .379 \\
Subjects & Within & 0.666 & 9 & 0.074 & & \\
& Total & 8.107 & 89 & & & \\
Professional & Between Groups & 6.171 & 64 & 0.096 & 1.245 & .276 \\
Education Subjects & Within & 1.936 & 25 & 0.077 & & \\
& Total & 8.107 & 89 & & & \\
\hline
\end{tabular}

${ }^{*} p<.05$

Table 6 represents the Analysis of Variance (ANOVA) to compare the academic procrastination of the respondents in the different subject areas. As seen, there is a significant difference in terms of the major subjects, $F(31,58)=1.663, p=.047$. The $F$ value is lower than the Alpha significance level of .05 , thus, there exists a significant difference in the academic procrastination practice of freshmen students in terms of major subjects. This means that since freshmen students have different major subjects per program, this can affect the prevalence of procrastination in studying.

Conversely, there are no significant differences in the academic procrastination of freshmen students in terms of general education subjects, $F(80,9)=1.257, p=.379$; professional education subjects, $F(64,25)=1.245, p=.276$; and grade point average (GPA), $F(83,6)=1.309, p=.400$. This is because their $F$ values are higher than the Alpha level of significance of .05. This means that in terms of general education subjects, and professional education subjects, the prevalence of academic procrastination cannot be implied. The same can also be said in terms of grade point average wherein it may or may not influence freshmen students to resort to academic procrastination.

Table 7 shows the correlation matrix between the academic procrastination of the respondents and the different subject areas. Based on the results of the study, academic procrastination is related to general education subjects, $\mathrm{r}=-.260, p=0.013$; professional education subjects, $\mathrm{r}=-.215, p=.042$. This is because their $r$-values are lower than the Alpha level of significance of .05 . This means that there is a low-negative relationship that exists between general education subjects, professional education subjects, and academic procrastination among freshmen students.

However, the major subjects, $\mathrm{r}=-.043, p=.688$ and grade point average (GPA), $\mathrm{r}=-.186, p=.079 \mathrm{did}$ not yield sufficient score to have a relationship with academic procrastination. This is because their $\mathrm{r}$ values are higher than the Alpha significance level of .05. This means that there is no relationship between major subjects, grade point average (GPA), and academic procrastination among freshmen students. 
Table 7. Relationship between Academic Procrastination and Subject Areas

\begin{tabular}{lccccc}
\hline & $\mathbf{1}$ & $\mathbf{2}$ & $\mathbf{3}$ & $\mathbf{4}$ & $\mathbf{5}$ \\
\hline Academic Procrastination & 1 & & & & \\
Major Subjects & -.043 & 1 & & & \\
& $(.688)$ & & & \\
General Education Subjects & $-.260^{*}$ & $.268^{*}$ & 1 & & \\
& $(.013)$ & $(.011)$ & & & \\
Professional Education Subjects & $-.215^{*}$ & $.335^{* *}$ & $.775^{* *}$ & 1 \\
& $(.042)$ & $(.001)$ & $(.000)$ & & 1 \\
Grade Point Average & -.186 & $.656^{* *}$ & $.866^{* *}$ & $.873^{* *}$ & \\
& $(.079)$ & $(.000)$ & $(.000)$ & $(.000)$ & \\
\hline
\end{tabular}

$* p<.05$

$* * p<.01$

\section{Discussions}

The main aim of this study is to analyze the demographic profile, the academic procrastination of freshmen students, and its relationship to their academic performance. The result could be a basis for an intervention in the programs that were included in the study.

This study found that respondents tend to procrastinate with their academics. About the result of the study, a team of researchers indicated that academic procrastination affects the frequency of all forms of academic misconduct [2]. However, another study contradicted the former and suggested that social and environmental factors should be given attention to reduce and prevent academic procrastination [24].

The researcher chose the three subject areas as the basis for academic performance to see whether these three have a connection to academic procrastination. As stipulated, academic procrastination has a negative relationship to academic performance [10]. Based on the result of this recent study, the average ratings per subject area do not vary that much. However, in the area of professional education subjects, this is the area where respondents take a dip and scored lower. Somehow, it affects their grade point average (GPA) to some extent. In connection, academic grades did not reveal differences to respondents, as procrastination was the same [25].

The study also observed some significant differences in the academic procrastination scales of the respondents when grouped according to their demographic profiles. Specifically, the program, scholarship status, and religion yielded substantial findings for this study. Parallel to this study, there was no significant difference between males and females from a research manuscript from an undergraduate perspective [18]. The researcher also observed the same evidence in this study. Since the study was only conducted in just two semesters, a study exposed that procrastination among students was related at the beginning of the semesters [15]. However, another research paper concurred that procrastination tendency is higher in the second year which does not coincide with the result of this study [18].

In terms of relationship, there has been a low negative relationship seen between academic procrastination of the respondents with the subject areas, namely: Professional Education Subjects and General Education Subjects. In association with the study's result, a paper showed that few students showed a high level of academic procrastination, over half of the students showed medium levels and approximately a quarter of students showed a low level of academic procrastination [26]. But a group of investigators showed the importance of looking at differences in how students deal with factors that negatively influence their learning [3]. Furthermore, two authors showed that academic procrastination has a negative effect on GPA [27].

With the results of the study, other pertinent literature that also provided some insights that may or may not support the concepts of this research. There are varied factors that affect the academic procrastination of a student. Some can root all from the parenting styles [26] and the behavior of the 
individual [28]. However, there are some cases that procrastination can be used in other ways like procrastination negatively predicted students' self-monitoring, goal setting, and pursuing goals relevant to self-regulated learning [29]. But a study suggested ways to motivate students to persist in academic self-efficacy and subjective task value through their relationships with academic procrastination [19]. Conversely, academic procrastination is a dynamic construct and offered the importance of early intervention [30]. Furthermore, active procrastination is related to the creative ideation of an individual [6], and students of learning habit type scores higher in tests than students of the procrastination type [31].

Finally, academic procrastination can be seen as a context that affects and plagues students. In this study, we did a simple assessment if such an event is prevalent and it has shown some significant results somehow.

\section{Conclusion}

Based on the following results, the researcher concluded on the following: (1) the respondents were English major, belong to 15-20 years old age bracket, female in the majority, have an average family monthly income of 5,001-10,000 pesos, Roman Catholics, and student-scholars. (2) The respondents agreed that they tend to procrastinate with their academic responsibilities. (3) The respondents' academic performance includes the following scores: for general education subjects, 89.34 (very good), for major subjects, 89.76 (very good), for professional education subjects, 86.10 (good), and grade point average (GPA), 88.58 (very good). (4) There were significant differences found when the respondents' academic procrastination response is grouped according to the program, scholarship status, and religion. And, (5) there is a low negative relationship between academic procrastination and the subject areas of general education subjects, and professional education subjects.

There are also several limitations in this study which include (1) the number of respondents in the study, (2) coverage of the study (the study only considered one institution), (3) the statistical analysis, and (4) the variables that played in the study. The researcher highly endorses other researchers to dwell upon these areas and expand further.

Based on these results, the researcher recommends the following (1) for the parents, it is advisable to monitor and guide our children concerning their undertakings whether it is at home, at school, or other extracurricular activities. (2) A flexible class routine of activities for instructors to eliminate the issue. (3) Monitor instructors/ faculty in giving deadlines for assignments, projects, and the like. It should be time bounded and realistic and achievable based on the ability of the students. (4) Provide live, classroom-based activities that will encourage student participation and reduce the burden of assignments and paper works. (5) Constant reminders and updates before, during, and after classroom discussions for the upcoming activities and lessons. (6) Provide seminars for effective classroom management against academic procrastination for instructors and department heads. And (7) conduct a more in-depth study about academic procrastination and its implication to the students.

\section{References}

[1] J. McCloskey, and S. A. Scielzo, "Finally! The development and validation of the academic procrastination scale," 2015. [Online] Available: https://doi.org/10.13140/RG.2.2.23164.64640. [Accessed: June, 5. 2020].

[2] J. Patrzek, and S. Sattler, "Investigating the effect of academic procrastination on the frequency and variety of academic misconduct: A panel study," Studies in Higher Education, vol. 40, no. 6, pp 1014-1029, 2015. doi: 10.1080/ 03075079.2013.854765.

[3] L.Visser, F. A. J Korthagen, and J. Schoonenboom, "Differences in learning characteristics between students with high, average, and low levels of academic procrastination: Students' views on factors influencing their learning. Frontiers in Psychology, vol. 9, pp. 1-15, 2018.

[4] K. R. Kim, and E. H. Seo, "The relationship between procrastination and academic performance: A meta-analysis," Personality and Individual Differences, vol. 82, pp. 26-33, 2015.

[5] J. Kim, H. Hong, et al, "Effects of time perspective and self-control on procrastination and internet addiction," Journal of Behavioral Addictions, vol. 6, no. 2, pp. 229-236, 2017. 
[6] W. Liu, and Y. Pan, "Active procrastination and creative ideation: The mediating role of creative self-efficacy," Personality and Individual Differences, vol. 119, pp. 227-229, 2017. doi: doi.org/j.paid.2017.07.033.

[7] Z. Zacks, and M. Hen, "Academic interventions for academic procrastination: A review of the literature," Journal of Prevention \& Intervention in the Community, vol. 46, pp. 117-130, 2018. doi: 10.1080/10852352.2016.1198154.

[8] S. Dev, "Effects of procrastination behavior, stress tolerance, and study habits on academic achievements of Indian Students residing in India (Kerala) and UAE," Research in Social Sciences and Technology, vol. 3, no. 3, pp. 16-31, 2018.

[9] F. M. Sirois, and R. Kitner, "Less adaptive or more maladaptive? A meta-analytic investigation of procrastination and coping," European Journal of Personality, vol. 29, no. 4, pp. 433-444, 2015.

[10] M. Balkis, and E. Duru, "Gender differences in the relationship between academic procrastination, satisfaction with academic life, and academic performance," Electronic Journal of Research in Educational Psychology, vol.15, no.1, pp. 105-125, 2017. doi: 10.14204/ejrep.41.16042.

[11] J. W. You, "Examining the effect of academic procrastination on achievement using LMS data in e-learning," Educational Technology \& Society, vol. 18, no. 3, pp. 64-74, 2015.

[12] X. Shi, and S. Wang, "Are procrastinators psychologically healthy? Association between psychosocial problems and procrastination among college students in Shanghai, China: a syndemic approach," Psychology, Health \& Medicine, vol. 24, no. 5, pp. 570-577, 2019. doi: 10.1080/13548506.2018.1546017.

[13] L. M. Closson, and R. R. Boutilier, "Perfectionism, academic engagement, and procrastination among undergraduates: the moderating role of honors student status," Learning and Individual Differences, vol. 57, pp. 157-162, 2017.

[14] S. Kim, S. Fernandez, and L. Terrier, "Procrastination, personality traits, and academic performance: when active and passive procrastination tell a different story," Personality and Individual Differences, vol. 108, pp. 154-157, 2017. doi: 10.1016/j.paid.2016.12.021.

[15] S. Yerdelen, A. McCaffrey and R. M. Klassen, "Longitudinal examination of procrastination and anxiety, and their relation to self-efficacy for self-regulated learning: Latent growth curve modeling," Educational Sciences: Theory \& Practice, vol. 16, no. 1, pp. 5-22, 2016.

[16] A. G. Umerenkova, et al, "A linear empirical model of self-regulation on flourishing, health, procrastination, and achievement, among university students," Frontiers in Psychology, vol. 9, pp. 1-12, 2018.

[17] R. J. Lowinger, B.C.H Kuo, et al, "Predictors of academic procrastination in Asian international college students," Journal of Student Affairs Research and Practice, vol. 53, no. 1, pp. 90-104, 2016. doi: 10.1080/19496591.2016.1110036.

[18] M. Stewart, T. Stott, and A. M. Nuttall, "Study goals and procrastination tendencies at different stages of the undergraduate degree," Studies in Higher Education, vol. 41, no. 11, pp. 2028-2043, 2016.

[19] F.Wu and W. Fan, "Academic procrastination in linking motivation and achievement-related behaviors: a perspective of expectancy-value theory," Educational Psychology, vol. 37, no. 6, pp. 695-711, 2015.

[20] Z. Yang, K. Asbury, and M.D. Griffiths, "An exploration of problematic smartphone use among Chinese university students: associations with academic anxiety, academic procrastination, self-regulation, and subjective well being," International Journal of Mental Health Addiction, 2018. doi: 10.1007/s11469-018-9961-1.

[21] J. F. M. Olano, and C. H. Parrado, "Effects of goal clarification on impulsivity and academic procrastination of college students," Revista Latinoamericana de Psicologia, vol 49, pp. 173$181,2017$.

[22] J. Gagnon, F. Dionne, and T.A. Pychyl, "Committed action: An initial study on its association to procrastination in academic settings," Journal of Contextual Behavioral Science, vol. 5, no. 2, pp. 97-102, 2016. doi: 10.1016/j.jcbs.2016.04.002.

[23] I. S. Hairston, and R. Shpitalni, "Procrastination is linked with insomnia symptoms: The moderating role of morningness-eveningness," Personality and Individual Differences, vol. 101, pp. 50-56, 2016. doi: 10.1016/j.paid.2016.05.031. 
[24] K. Nordby, K.B. Klingsieck, and F. Svartdal, "Do procrastination-friendly environments make students delay unnecessarily?" Social Psychology of Education, vol. 20, no. 3, pp. 491-512, 2017.

[25] C. N. Alfonso, D. Peñaranda, J. Vicente and F. M. "Jimenez Procrastination: the poor time management among university students," Editorial Universitat Politecnica de Valencia. vol. 1, no. 8, 2018. doi: 10.4995/HEAD18.2018.8167.

[26] A. M. Mahasneh, O.T. Bataineh and Z. H. Al-Zoubi, "The relationship between academic procrastination and parenting styles among Jordanian undergraduate university students," The Open Psychology Journal, vol. 9, pp. 25-34, 2016. doi: 10.2174/1874350101609010025.

[27] M. Goroshit, and M. Hen, "Academic procrastination and academic performance: Do learning disabilities matter? Current Psychology, vol. 1, no. 9, 2019. doi: 10.007/s12144-019-00183-3.

[28] Y. Xie, J. Yang and F. Chen, "Procrastination and multidimensional perfectionism: A metaanalysis of main, mediating, and moderating effects," Social Behavior and Personality: An international journal, vol. 46, no. 3, pp. 395-408, 2018. doi: 10.2224/sbp.6680.

[29] J. C. Hong, M. Y. Hwang, Y. C. Kuo, and W. Y. Hsu, "Parental monitoring and helicopter parenting relevant to vocational student's procrastination and self-regulated learning," Learning and Individual Differences, vol. 42, pp. 139-146, 2015. doi: 10.106/j.lindif. 2015.08.003.

[30] N. Ziegler, and M. C. Opdenakker, "The development of academic procrastination in first-year secondary education students: The link with metacognitive self-regulation, self-efficacy, and effort regulation," Learning and Individual Differences, vol. 64, no. pp. 71-82. 2018.

[31] Y. Goda, M. Yamada, H. Kato, T. Matsuda, Y. Saito and H. Miyagawa, "Procrastination and other learning behavioral types in e-learning and their relationship with learning outcomes," Learning and Individual Differences, vol. 37, pp. 72-80, 2015. doi: 10.1016/j.lindif. 2014.11.001. 